\title{
The Implementation of Environmental Impact Assessment (EIA) Regulations in the Construction of Low Cost Houses in Newcastle, South Africa
}

\author{
Shadung John Moja ${ }^{1} \&$ Simphiwe Ntokozo Mnguni ${ }^{1}$ \\ ${ }^{1}$ Department of Environmental Sciences, University of South Africa, Florida Campus, Roodepoort, South Africa \\ Correspondence: Shadung John Moja, Department of Environmental Sciences, University of South Africa, \\ Florida Campus, Roodepoort, South Africa. Tel: 27-114-713-878. E-mail: mojasj@unisa.ac.za; \\ shadung@yahoo.com
}

Received: August 8, 2013 Accepted: September 23, 2013 Online Published: September 15, 2014

doi:10.5539/jas.v6n10p1 URL: http://dx.doi.org/10.5539/jas.v6n10p1

\begin{abstract}
An increase in global population is coupled with intensive growth in residential development. This has resulted to development in land that is unsuitable for occupancy generating negative consequences to the surrounding communities in the long run. In line with the above the study intended to determine if the implementation of EIA regulations in the construction of Reconstruction and Development Programme (RDP) houses, which are in close proximity to the wastewater treatment plants (WWTP) was adequately followed in Newcastle. It is essential that an EIA is carried out to determine significant impacts early in the project cycle so that recommendations can be built into the design without causing major negative impacts in the future. The study was to identify possible health effects which are attributed to the proximity of the WWTP to the residential area. This study involved participants who resided in close proximity to the site, those who are located five kilometers away, the healthcare givers and the municipality officials. About $68.0 \%$ of the respondents believe that the WWTP has negative effects on their lives while $36.0 \%$ said the WWTP has negative effects on the environment. The outcome of this study revealed that EIA regulations were not adequately implemented and that this residential site was unsuitable for the construction of RDP houses. The study further reveals that public participation is not highly considered yet high participation from the public leads to a comprehensive and better decision making. It also safeguards against bad or politically motivated decisions. The dominant civic organization has also been weakened when influential leaders were co-opted into the leadership structure of the local authority since they were in alliance with the ruling party. The need and pressure to meet election promises could have also blindsided the new political elites, which led them to ignore their own regulations. It's crucial that developers look at the KwaMathukuza case study to see how poor EIA practice can affect economic, social, morbidity and mortality risks, cumulative and intergenerational effects, and broader determinants of health which could have been avoided.
\end{abstract}

Keywords: environment, wastewater treatment plant, environmental impact assessment, low cost housing

\section{Introduction}

In the early 1990s South African government undertook the RDP, which was aimed at addressing housing shortages in the country. One of the key principles of the RDP, in relation to housing, read as follows "Provide well-located and affordable shelter for all" (Huchzermeyer, 2001). The Department of Human Settlements acknowledges that access to well located land is one of the major blockages in the housing delivery chain (DHS, 2012).

The EIA is there to promote sustainable development by ensuring that any large scale development does not undermine critical resource and ecological functions or the wellbeing, lifestyle and livelihood of the communities who depend on them (Gaudreau \& Gibson, 2010). It implies that any housing effort intended to uplift social development needs to comply with the EIA regulations. This will ensure an economical and sustainable development. It is important that provisions and recommendation of EIA are correctly followed in order to ensure that informed decisions that support the achievement of sustainable development are considered. 
Since the authorities were responsible for this development, it was imperative that their actions be evaluated or audited independently to ensure fairness and transparency.

Wastewater treatment plants (WWTPs) are critical infrastructures for any modern city. They have historically, by virtue of odour and perception impacts, been located away from residential areas, and have been provided with buffer zones - more related to distance than specific odour modelling and odour mitigation strategies (BCC, 2007). The main function of a WWTP is to minimize the environmental impact of discharging untreated water into natural water systems (Al-Jasser, 2011). The WWTPs form part of the water reuse strategy whereby wastewater from different sources is cleaned and released back into lakes and rivers. Before the final effluent is released into the receiving waters, it may be disinfected to reduce the disease-causing microorganisms that remain in it.

The noticeable gases that are perceived as odour from WWTPs can have a detrimental impact on the quality of the local environment for those living close by, yet water treatment plant works are essential for maintaining standards in water quality. Brunner and Fellner (2007) agree that the location of any WWTP should be as far as practical from public dwellings places. Considerably so developers cannot just locate any site for their developmental projects rather in-depth studies need to be first conducted to ensure that a particular land is secure and conducive even when the population increases beyond what was envisaged. In that way EIA needs to be considered to protect the environment and to prevent, control and abate pollution and environmental harm (Bond \& Morrison-Saunders, 2011). It goes without say that clean water is essential but public health is also crucial to ignore the odour nuisance.

The South Africa's Constitution (1996), Section 24 guarantees all its citizens the right to an environment that is not harmful to their health and well-being. However the constitution appears to be ignored if in principle is not applied to solve any issues that concern the wellbeing of society. It emerges strongly therefore to question the regulations that govern the building of housing systems in KwaMathukuza, Newcastle if the municipality only worried about providing shelter and ignored the health impacts and many other possible environmental impacts that may be associated with weak developmental policies and regulations.

This particular study intended to investigate if the integrated EIA regulations were effectively implemented before building the RDP houses at kwaMathukuza Section, in Newcastle which has been labeled as 'emanukwini' which means the filthy place in Northern KwaZulu Natal. In KwaMathukuza people reside in close proximity to a WWTP. Given all the possible health hazards much research was needed to investigate the extent of implementation of EIA regulations before the RDP houses for these communities were built.

\section{Materials and Methods}

This study used a mixed method approach because the researcher concurs with scholars (Mnguni, 2012; Creswell, 2009) who argue that mixing methods strengthen research findings; in that each approach is validated by the other when used together. The quantitative method instrument consisted of open ended and closed ended questionnaires which were given to all participants. Open ended questions allow for a greater variety of responses from participants and the closed ended questions on the other hand are easy to analyse statistically but they limit the responses of the participants (Jackson, 2009). Semi- structured interviews were also held with participating municipal officials. Such interviews provide rich and well-grounded explanations on the investigated subject.

\subsection{Sampling}

The first set of data was collected at KwaMathukuza in Newcastle due to its close proximity to the WWTP. The study aimed for a demographically representative sample. A non-probability sampling was used where convenience sampling where accessible participants were selected. In this regard, a stratified sampling technique was applied to divide the entire target population into different subgroups (Figure 1), or strata, and then randomly selected the final participants proportionally from the different strata. This type of sampling is used when an adequate amount of participants is wanted from each strata in the final sample (Cresswell, 2012). The selected participants were then given the questionnaire for data collection. 


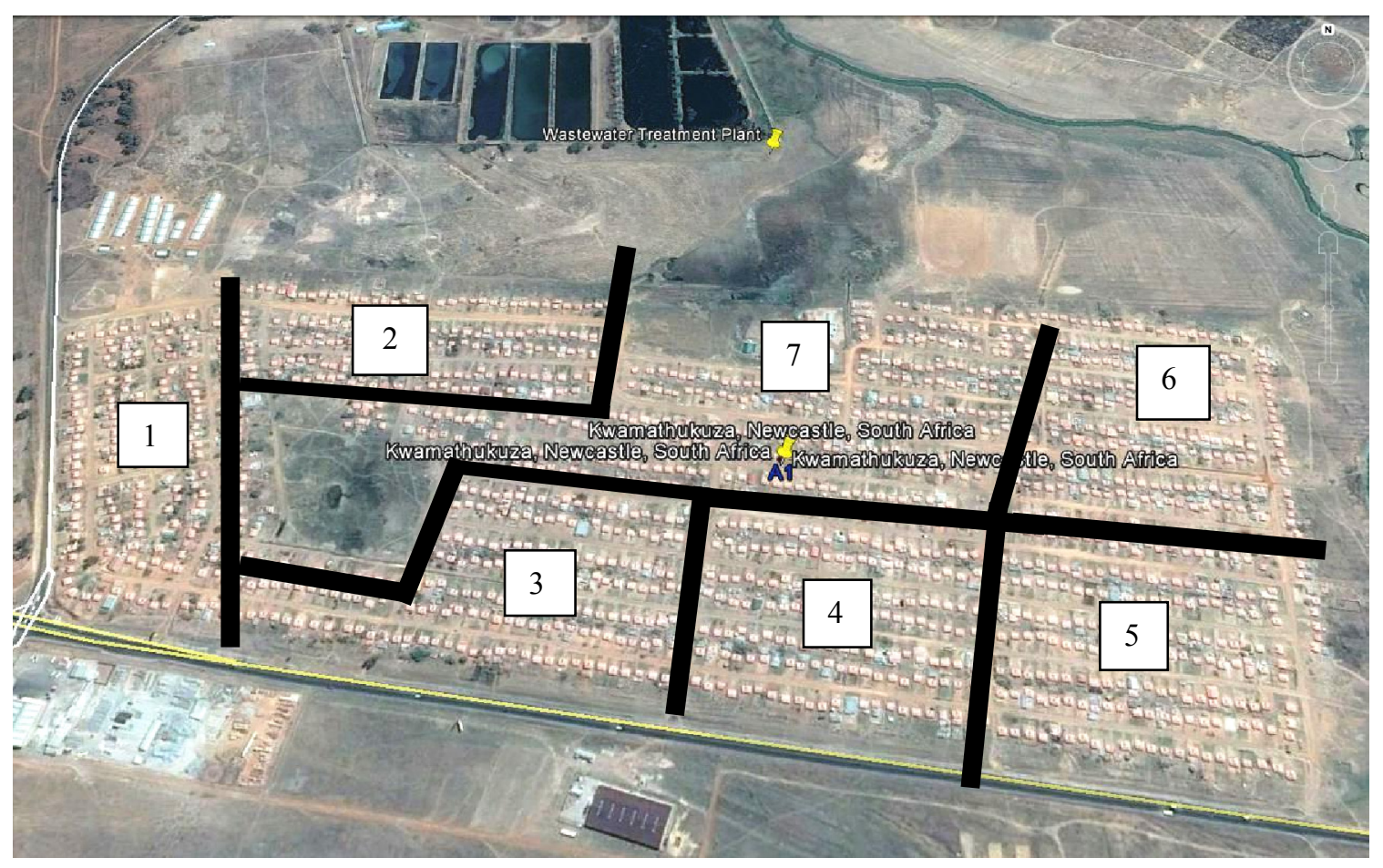

Figure 1. Shows the numbers which represent the groupings of populations in the study area

The target survey included 85 residents in the area, both male and female between the age group $18-65$ years due to their ability to give reasonable answers. With regards to neighbouring residents who reside more than five kilometers from the WWTP, ten people were surveyed to determine the extent of the impact. About 10 health caregivers were involved in the study because the researcher believes they are there to oversee the health of people in the area, provide sound advice on rehabilitating their health and ensure that they administer appropriate treatment based on their health status and surrounding environment. The input from a municipality official who is involved with the WWTP was crucial as the researcher believed that the official may provide information on the technical aspects of the plant that may be manipulated in the future to reduce the impact of the odour to the surrounding community. Unfortunately, the researcher was unable to secure an interview with senior officials despite several attempts'.

Ethical clearance for undertaking the study was granted by the University of South Africa (Ref. Nr: 2012/CAES/046). Among the significant ethical issues that were considered in the research process include consent and confidentiality. Participation in the study was voluntary, there were no benefits associated with answering the questionnaire.

\subsection{Questionnaire Design and Validation}

The questionnaire was validated by utilizing the face validity method because of its simplicity and it helps the researcher determine if the questionnaire measures what is intended to measure. In this regard, ten randomly chosen people were given a validation questionnaire to scrutinize each instrument and determine its legitimacy and appropriateness for the research. These questions were designed to address two fundamental questions, through which the validity of the instruments would be established:

a) Does the instrument question what they ought to be? Given that each section of the instrument was meant to assess some specific information and to determine whether the instrument met the specified standards.

b) Is the instrument suitable for the purpose it is designed for? In this instance the main focus was on the conceptual background of the instrument as per propositional knowledge.

The content validity method was measured using the Statistical Programme for Social Sciences (SPSS) to strengthen the validation. The content validity index (CVI) was calculated and validity of the questionnaire was based on scoring. As suggested by Hyrkäs et al. (2003), questionnaires that score above 0.79 are regarded as 
acceptable, those between 0.7 and 0.78 as in need of attention and those below 0.69 as requiring revision or elimination. This particular method showed that the instrument was valid and reliable due to the 0.80 score obtained by the researcher. Therefore, at the end of this process the researcher was confident that the instrument was valid and suitable for the research.

\subsection{Data Collection and Analysis}

The final questionnaire was administered for data collection where responses were analyzed to identify the most prominent trends. The initial step of the analysis was:

- Gathering together information from all sources and observations.

- Making photocopies of all recording forms and any other collected materials, to guard against loss, accidental erasure, or other problems.

- Entering narratives, numbers, and other information into a computer program, where they can be arranged and/or worked on in various ways.

- Coding data in a way that make them easier to work with.

Analyzing information involves examining it in ways that reveal the relationships, patterns, trends, etc. that can be found within it. That may mean subjecting it to statistical operations that can tell you not only what kinds of relationships seem to exist among variables, but also to what level you can trust the answers you're getting. It may mean comparing your information to that from other groups (a control or comparison group, statewide figures, etc.), to help draw some conclusions from the data. The point, in terms of your evaluation, is to get an accurate assessment in order to better understand your work and its effects on those you're concerned with, or in order to better understand the overall situation.

\section{Results}

\subsection{Background Information of the Respondents}

The results show that $99.0 \%$ of the sampled community is black African except for $1 \%$ minority which is coloured people. The results further indicate that $55.0 \%$ of the respondents were females and $45.0 \%$ were males. The unemployed respondents amount to $73.0 \%$, whereas $13.0 \%$ is self-employed and $12.0 \%$ is employed. In terms of education, $52.0 \%$ of the respondents have high school education (i.e. Grade 8 to 12 ), $9.0 \%$ studied at FET colleges, $4.0 \%$ studied at university, $3.0 \%$ have primary school education and $7.0 \%$ never obtained any formal education.

This community is made largely of poor people, hence the government decided to build low cost houses for them. Reasons of high rate of the unemployed in the area include the nonexistence of a high school and the high prevalence of HIV pandemic that force children out of schools and to fend for their younger siblings. Most members of this community do not have the required education and skills for the available jobs since only about $13 \%$ have post high school qualifications,

Thirty one percent of the respondents were aged between 26.0-35.0 years. Forty two percent of the respondents had been residing in the area for 6.0-10.0 years at the site, during which time the water treatment facility was operational (Figure 2).

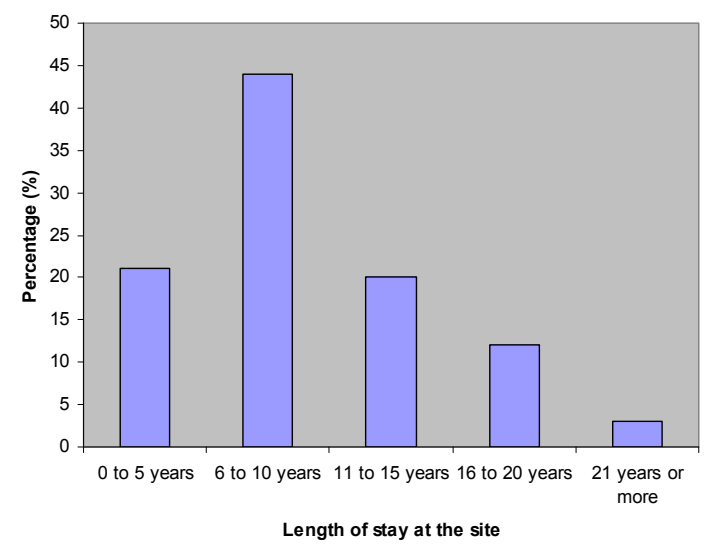

Figure 2. \% Length of stay of sensitive receivers at the site 


\subsection{Compliance With EIA Regulations}

This study discovered that an EIA study was conducted before houses were built at KwaMathukuza in 2003. The municipality official (i.e. respondent \#5) indicated that "the approval for building houses in KwaMathukuza was received on the $25^{\text {th }}$ November 2002" from the Development Tribunal. The Development Tribunal was established in terms of Section 15 (1) of the Development Facilitation Act, Act No 67 of 1995, with one of its primary functions being to consider and decide upon land development applications submitted in terms of the Act. A tribunal is established for each province in each case to be known as the development tribunal of the province concerned. A tribunal consists of a chairperson, a deputy chairperson and approximately 50 other member appointed by the Premier with the approval of the provincial legislature.

Unfortunately, a written decision which calls for either an Environmental Authorization or Environmental Refusal that is listed in a Record of Decision (RoD) could not be accessed and the study depended only on information that came from the local Department of Environmental Affairs (DEA) officials. The official (from the DEA, respondent \#20) indicated that EIA was done and some of the concerns which exist today were brought into light by that study however no action was taken to stop the building progress from the site. These concerns included the close proximity of the WWTP to the site, the cemetery and the river. Respondent \#5 (a municipality official) argued that "it doesn't take a rocket scientist to see that the area was and is unsuitable for human habitation" even though houses were build there. This finding suggests that while the EIA was conducted by the DEA, its recommendations were not implemented. As a consequence, it emerged (from a municipality official, respondent \# 9) that the "Provincial Department of Environmental Affairs has made a court application accusing the municipality, specifically the Town Planning division, of being indecorous in allowing such a site to be occupied". The court case is still pending and relevant documents could not be obtained due to the sensitivity of the matter.

The study further investigated how the houses were built against the recommendations of the EIA. The division of Town Planning in the municipality, through respondent \#11, indicated that the reason why the establishment continued was due to "the policies and Acts of that time". He indicated that they "complied mainly with the Development Facilitation Act 67 of 1995 which was enacted after 1994 from a transition of apartheid". He indicated that they interpreted the Act as one of:

"extraordinary measures to facilitate and speed up the implementation of reconstruction and development programmes and projects in relation to land; and in so doing to lay down general principles governing land development throughout the Republic. The Act further suggests that a development that benefits the environment [more than the society] should not be used to stop development, instead there must have mitigation measures to address the loop holes. This Act was less formal and applied mainly to the township establishments".

The respondent (\#11) openly indicated that the other aspect that led to the establishment of that site was the availability of land that solely belonged to the municipality and wasn't privately owned.

The Town Planning division (through respondent \#11) went on further to point out that the system on how they handle developmental issues especially with regards to RDP houses has "improved since the new Planning and Development Act 2010 which introduces provisions regarding development plans, changes to the planning code and has made significant amendments to the Planning and Development Act 2000 ("the 2000 Act")". These changes are relevant to developers, local authorities and all future applicants for planning permissions.

Given the finding that EIA recommendations were not implemented, the study went on to investigate whether follow-up audits have been done to determine the impact of building houses in an unsuitable area. Environmental auditing is an important tool for providing an account of post-development EIA activities. In the past much EIA auditing focused on predictive techniques and prediction accuracy, which provide little information on the actual environmental outcomes. However, of central interest in determining the effectiveness of EIA is the extent to which the environment and communities are managed and protected as a result of the EIA process as it is intended. The audit methodology for determining EIA effectiveness focuses on several distinct EIA components: impact prediction; occurrence of actual impacts; and the management of potential and actual environmental impacts. These are examined with particular attention to impact and environmental management outcomes. With regards to communities, auditing would include regular meetings between environmental management officials, municipalities and communities to determine if certain projects (such as the proximity of the residential area to the wastewater treatment plant) are causing harm to the community. It was expected that, since the EIA recommendations were not implemented at KwaMathukuza, regular meetings would be held between the relevant authorities and the community to ensure that the livelihood of the society is not compromised. About 
$46.0 \%$ of the respondents indicated that they have not attended any meetings with the municipality in general, while $44.0 \%$ have (Figure 3 ). The reasons of nonattendance of municipal meetings vary from late notices, unawareness, poor communication, general lack of interest and distrust of the motives of the officials.

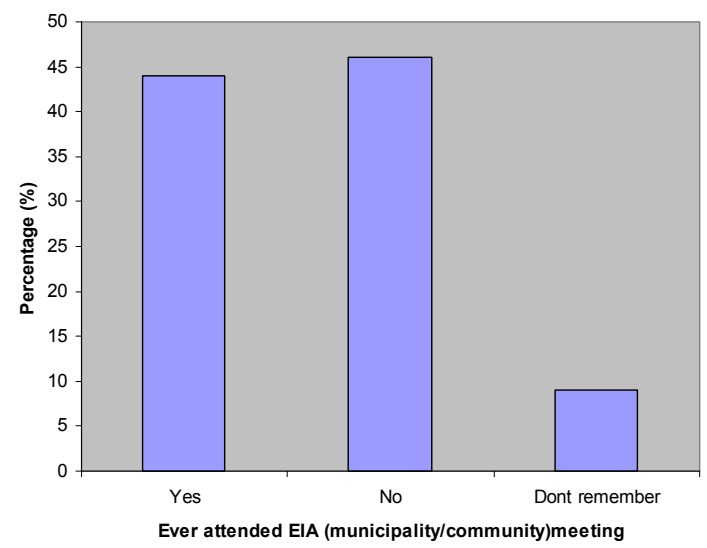

Figure 3. Showing the attendance to the municipality/community meetings

To this effect, $62.0 \%$ of the respondents indicated that they report environmental problems to their local council (not the municipality), 15.0\% report to municipality and 3.0\% choose not to report. In this regard, $60.0 \%$ of the respondents indicated having reported odour related complaints while $21.0 \%$ have not. Sadly $36.0 \%$ of the respondents indicated that their complaints and request are never resolved. To this end, $68.0 \%$ of the respondents believe that the WWTP has negative effects on their lives while $36.0 \%$ said the WWTP has negative effects on the environment. A critical observation in this instance is that there appears to exist poor communication between the municipality which administers the WWTP and the community at KwaMathukuza. This means the EIA measures to address environmental and social hazards such as proper and efficient auditing do not take place properly.

\subsection{Discussion}

The researcher found that EIA was conducted in the study area before building commenced. The initial plan for the housing process was based on the "fast-tracking" method, which translated into external contractors coming in and building houses speedily. The responses from the officials from the local office of Department of Environmental Affairs (DEA) signify that recommendations promulgated from the EIA were not in favour of building from that site. This means officially that site should not have been zoned for residential development.

It seems as though executive power was intimately used in disconcerting the EIA policy and applying other policies as indicated to develop the area. It is pleasing to see government being committed to sheltering people; however it is also disturbing that future implications of the consequences of building in the area were not properly looked. It must be noted that the local municipality still bears the burden in their limited budget to set aside funds for reconstruction of houses that were built in the unsuitable terrain. Rebuilding those houses may seem proper but it doesn't look like a sustainable solution.

The research found poor follow up at the site, residents were succumbing to atrocious living conditions and from their report "the municipality was doing little to attend to the residents' needs". The municipality had decided to plant trees to curb the odour only in 2011 which is 9 years later since the houses were built. Sadly many of the trees died because the local municipality expected the people to take care of the trees which didn't happen. Overall, there is little evidence that clearly indicated that EIA was adequately integrated in the housing projects. There is no evidence that policies and laws that relate to EIA contributed at promoting cognizant environmental management to evaluate potential environmental social, economic, cultural, natural impacts, socioeconomic impacts which include an assessment of land use, visual and aesthetic impacts on neighbours.

This study focused on the extent the EIA regulations were implemented to prevent health hazards in KwaMathukuza. Future explorations should focus on ensuring that the EIA practice improves. The researcher proposes more use of planning and obligations use including the expansion of the use of formalised Environmental Management Plans to deliver them. Furthermore, the researcher believes that there should be a 
body or professional institute that drives and monitors the implementation of the EIA regulations by practitioners.

\section{Conclusion}

The findings indicate that there may be lack of proper implementation of EIA following main steps, in line with international practice. This could be due to lack of enforcement from Environmental Management bodies. All the above factors indicate that EIA is mandatory in South Africa however developers may struggle to understand the authenticity of the process if it lacks proper implementation. It's crucial that developers look at the KwaMathukuza case study to see how a poor EIA practice can affect economic, social, morbidity and mortality risks, cumulative and intergenerational effects, and broader determinants of health which could have been avoided.

This study has also revealed the existence of a gap between policy and practice in the area of EIA. While the study was based on a small community in South Africa, the researchers believe that the same trends could be found in other places around the country. The results provide insights regarding the impact of the dilemma to provide service delivery at the cost of proper legislation. This knowledge is also critical for other developing countries that may face the same conflict of interest as South Africa. As a consequence, there is urgent need to explore and perhaps revise the role of EIA in South Africa against the backdrop of demand of service delivery. The study concludes that there's a need to improve the EIA administration system to ensure sustainable development.

\section{References}

Bond, A. L., Viegas, C. V., Coelho, C. C. R., \& Selig, P. M. (2010). Informal knowledge processes: the underpinning for sustainability outcomes in EIA? Journal of Cleaner Production, 18(1), 6-13. http://dx.doi.org/10.1016/j.jclepro.2009.09.002

Brennan. (1993). Odour nuisance. Wastewater Treatment, 36, 30-33.

Brunner, P. H., \& Fellener, J. (2007). Setting priorities for waste management strategies in developing countries. Waste Manage Res, 25, 234-240. http://dx.doi.org/10.1177/0734242X07078296

Creswell, J. W. (2009). Research design, qualitative, quantitative, and mixed methods approaches. Thousand Oaks: Sage publications.

Creswell, J. W., \& Plano-CLARK, V. L. (2007). Designing and conducting mixed methods research. Thousand Oaks: Sage Publications.

Department of Human Settlements (DHS). (2012). Annual Report 2011/2012. Retrieved February 15, 2013, from http://www.dhs.gov.za/uploads/annual reports/ annual-report-10112012.pdf

Gaudreau, K., \& Gibson, R. B. (2010). Illustrating integrated sustainability and resilience based assessments: a small-scale biodiesel project in Barbados. Impact Assess Proj Apprais, 28(3), 233-43. http://dx.doi.org/10.3152/146155110X12772982841122

Huchzermeyer, M. (2001). Housing for the poor? Negotiated housing policy in South Africa Original Research Article. Habitat International, 25(3), 303-331. http://dx.doi.org/10.1016/S0197-3975(00)00037-0

Kakonge, J. (2013). Improving Environmental Impact Assessment (EIA) Effectiveness: Some Reflections. Retrieved May 2, 2012, from http://www.globalpolicyjournal.com/blog/05/03/2013/improving -environmental-impact-assessment-eia-effectiveness-some-reflections

Maddocks. (2011). Water, Planning and Environment. Protecting the integrity of wastewater treatment plants through environmental and planning laws. Retrieved May 7, 2012, from http://www.maddocks.com.au/uploads/articles/protecting-the-integrity-of-wastewater-treatment-plants-upda te-may-2011.pdf

Mnguni, L. E. (2012). The relationship between the Grade 11 Life Sciences curriculum and HIV and AIDS behavior transformation of students. PhD Thesis, University of Pretoria, Pretoria.

Morrison-Saunders, A. R., Marshal, R., \& Arts, J. (2007). EIA Follow Up International Best Practice Principles. Special Publication Series No.6. Fargo, USA. International Association for Impact Assessment.

Ramli, R., Mohamed, M. Z., \& Zahari, R, K. (2012). The Contributions of Public Participation in Environmental Impact Assessment (EIA) towards Promoting Sustainable Development in Malaysia. Masters Thesis, International Islamic University Malaysia, Kuala Lumpur. 
Yusuf, T. A. (2008). The Environmental Impact Assessment Practice in Nigeria. The Journey So Far. Retrieved on May 6, 2013, from http://www.nigeriansinamerica.com/articles/3105/1/The-Environmental-ImpactAssessment-Practice-In-Nigeria-The-Journey-So-Far-/Page1.html

\section{Copyrights}

Copyright for this article is retained by the author(s), with first publication rights granted to the journal.

This is an open-access article distributed under the terms and conditions of the Creative Commons Attribution license (http://creativecommons.org/licenses/by/3.0/). 